\title{
Genetic Characterization of Aeromonas hydrophila using Protein Profiling and RAPD PCR
}

\author{
P.C. THOMAS ${ }^{1}$, P.R. DIVYA ${ }^{* 2}$, V. CHANDRIKA ${ }^{3}$ and M.P. PAULTON ${ }^{1}$ \\ ${ }^{1}$ Marine Biotechnology Division, CMFRI, Cochin - 682 018, India. \\ ${ }^{2}$ National Bureau of Fish Genetic Resources, Dilkusha Post, Canal Ring Road, \\ Lucknow- 226002, India. \\ ${ }^{3}$ Fisheries Environment and Microbiology Division, CMFRI, Cochin - 682 018, India.
}

\begin{abstract}
Genetic relationship among Aeromonas hydrophila isolates from fish and traditional brackishwater farms were evaluated through Randomly Amplified Polymorphic DNA (RAPD) analysis as well as Sodium Dodecyl Sulphate-Polyacrylamide Gel Electrophoresis (SDS PAGE) profile of cellular proteins. PCR amplification of the DNA from the bacterial isolates using five random primers (OPA-01, 03, 04, 05 and 10) produced 46 amplicons, which were scorable as distinct bands on agarose gel electrophoresis. Absolute polymorphism of RAPD profile was evident with a unique pattern for each isolate, indicating its usefulness as an ideal tool for evaluation of genetic heterogeneity within the species, which are not revealed by other methods like morphological and biochemical characterization and cellular protein profile. Cellular protein profile did not reveal significant polymorphism as all the isolates revealed uniform pattern indicating its usefulness as a tool for species level identification. Four protein bands of molecular size viz., $19.5 \mathrm{kDa}, 25.6 \mathrm{kDa}, 29 \mathrm{kDa}$ and $65.6 \mathrm{kDa}$ were shared by all the isolates in the study.
\end{abstract}

\section{Introduction}

Aquaculture has grown significantly during the past decade. However, the aquaculture industry faces several problems that have to be solved before it can achieve and sustain significant growth as an industry. Disease is one of the major threats faced by this industry.

Role of the motile aeromonad, Aeromonas hydrophila as an etiological agent in fish and shellfish disease is highly significant. Although the outcome of disease by this secondary pathogen mostly depends on the presence of a primary pathogen, it is well recognized as a primary pathogen also (Miyata et al.1995).

Aeromonas hydrophila (Chester 1901); Stanier (1943) is a gram negative, facultatively anaerobic, motile, waterborne bacterium with wide distribution. They have long been known to be pathogenic to cold and warm-blooded fauna. Since 1960 the

\footnotetext{
* Corresponding Author.

Email : divyanbfgr@gmail.com
} 
potential of these organisms to cause diseases in human has been recognized. In humans and other mammals, A.hydrophila has been reported as the causative agent of numerous manifestations associated with gastroenteritis, systemic infections and bacterial endocarditis. In amphibians, reptiles, and fishes, these organisms have reportedly been associated with necrotic septicaemic and ulcerative diseases (Austin and Austin 1993; Inglis 1993; Olafse et al. 1993). Though the exact role of A.hydrophila in disease still remains in a state of flux, it is accepted as an opportunistic pathogen of homeothermic and poiekilothermic hosts.

To determine the health risks in aquatic environment associated with the exposure to A. hydrophila, epidemiological tracking is required. Conventional methods used for bacterial identification are tiresome, time consuming and not fit for mass scale screening of bacteria. Microbial molecular genetics is gaining popularity in recent times as an essential tool in the classification of the microbes.

Arbitrary/Random primed PCR amplification of DNA (AP-PCR/RAPD) has been increasingly reported as a method for the genetic characterization of microorganisms. The advantages of this method for the characterization of Listeria monocytogenes, Vibrio vulnificus, Aeromonas salmonicida and Bacillus thuringiensis have already been reported by Lawrence et al. (1993), Covadonga et al. (1998), O’hlei et al. (2000) and Pattanayak et al. (2001) respectively. Cellular proteins are the expressions of genetic information coded in the DNA and therefore the protein profile reveals the functional genetic diversity. Mc Lean et al. (1993) and Das et al. (2005) have observed that protein profiling has application in the characterization, classification and identification of bacterial isolates.

In the present study, the genetic heterogeneity and phylogenetic relationship among Aeromonas hydrophila isolates from the tissues of moribund fishes (Etroplus suratensis) and the waters of traditional brackishwater farms in the Cochin region of Kerala State (along south west coast of India) were evaluated using the RAPD profile and the cellular protein profile resolved through Sodium Dodecyl Sulphate-Polyacrylamide Gel Electrophoresis (SDS PAGE)

\section{Materials and methods}

\section{Bacterial Isolates}

Twenty-eight isolates of Aeromonas hydrophila from the tissues of moribund fishes (Etroplus suratensis) and the waters of traditional brackishwater farms in Cochin were used in this study. Isolation of Aeromonas hydrophila was done using selective medium, Rimler Shotts agar (Hi Media). The plates were incubated at room temperature (RT $28^{\circ} \mathrm{C}$ for 48 hours). All cultures were identified to the species level using differential biochemical tests (Table 1). Selected Aeromonas hydrophila colonies were subcultured in peptone water for further molecular characterization. 


\section{RAPD-PCR Analysis}

\section{DNA Extraction}

The protocol developed by Murray and Thompson (1980) with modifications was used for isolation of DNA from broth culture of the bacteria at log phase. The modified protocol without the use of proteinase $\mathrm{K}$ has given good result, yielding quality DNA of approximately $20 \mu \mathrm{g}$ from a $2 \mathrm{ml}$ bacterial culture.

\section{Primers}

A panel of 20 numbers of decamer random primers from M/S Operon Technologies, designated as OPA-1 to OPA-20 was used for PCR amplification of the bacterial DNA template. Five out of these 20 primers, viz., OPA-01, OPA-03, OPA-04, OPA-05 and OPA-10 were selected for final screening as they only generated several reproducible amplicons that could be resolved as distinct bands by agarose gel electrophoresis.

\section{PCR amplification and resolution of RAPD markers}

PCR reactions has been optimized for important parameters such as annealing temperature, concentration of $\mathrm{MgCl}_{2}$, template DNA, Taq DNA polymerase, d NTP's and primers. The PCR reaction components consists of $200 \mathrm{~mm}$ dNTP, 7.5 pico moles of primer, 2 units of Taq DNA polymerase enzyme, assay buffer with working concentration of $1.5 \mathrm{mM} \mathrm{Mgcl}_{2}, 20-30 \mathrm{ng}$ template DNA in an assay volume of $25 \mathrm{ml}$. These concentrations were determined by a series of preliminary standardizing experiments.

Thermal cycling was performed with Perkin-Elmer thermocycler (GeneAmp PCR System 2400). Each of the 35 PCR cycles standardized for this work consisted of denaturation of DNA at $92^{\circ} \mathrm{C}$ for one minute, primer annealing at $37^{\circ} \mathrm{C}$ for one minute and primer extension at $72^{\circ} \mathrm{C}$ for one minute. All PCR samples were subjected to an initial two minutes denaturation for $94^{\circ} \mathrm{C}$ and post amplification extension at $72^{\circ} \mathrm{C}$ for ten minutes. PCR products were stored at $-20^{\circ} \mathrm{C}$ until electrophoresis was performed.

The PCR amplification products were resolved by carrying out electrophoresis using a $1.5 \%$ agarose gel, stained with ethidium bromide. The marker used was $\lambda$ DNA cut with HindIII/EcoRI. The DNA bands were visualized and documented using a Vilber Lourmat Gel documentation system.

\section{Phylogenetic Analysis}

Amplified DNA fragments resolved as bands on the gels were used to generate the data matrix by giving scores of zero and one for the absence or presence of bands, respectively, at each band position. The data matrix of individual primers was finally 
joined to form a single matrix. Parameters like overall amplicon frequency at each locus, number and percentage of polymorphic loci, Nei's gene diversity and Nei's original measures of genetic identity and genetic distances between the isolates were estimated from the RAPD data using the POPGENE under Microsoft Windows 3.11 (Yeh et al. 1997).

\section{Bacterial Protein Isolation and SDS PAGE}

Aeromonas hydrophila were harvested from $2 \mathrm{ml}$ broth culture during the post logarithmic phase by spinning at $10000 \mathrm{rpm}, 4^{\circ} \mathrm{C}, 10$ minutes in $1.5 \mathrm{ml}$ eppendorf tubes in a refrigerated high speed centrifuge. The supernatant was drained off and $100 \mu \mathrm{l}$ of Tris, EDTA, Glucose buffer ( $\mathrm{pH} 8$ ) containing $5 \mathrm{mg} / \mathrm{ml}$ lysozyme was added to each of the pellets and vortexed in a vortex mixture machine. This was incubated at $4{ }^{\circ} \mathrm{C}$ for 15 minutes, mixing gently every five minutes. The cell suspension was then centrifuged at $10000 \mathrm{rpm}, 4^{\circ} \mathrm{C}, 10$ minutes and the supernatant was collected in eppendorf tubes and stored at $-20^{\circ} \mathrm{C}$ for further use. SDS PAGE carried out in the present study was on the lines of Laemmeli et al. (1970).

\section{Results}

Aeromonas hydrophila appeared as flat yellow colonies with entire margin in the Rimler shotts medium. In primary characterization tests, they were gram negative, rod shaped, motile, oxidase positive, fermentative, 0/129 resistant and novobiocin resisitant, suggesting that colonies are aeromonads. All isolates were confirmed to the species level Aeromonas hydrophila by differential tests given in Table 1 .

Table 1. Characteristics of bacteria isolated in the study.

\begin{tabular}{lcll}
\hline \multicolumn{1}{c}{ Test } & Characteristics & \multicolumn{1}{c}{ Test } & Characteristics \\
\hline Gram stain & + & Ornithine decarboxylase & + \\
Shape & Rods & H2S production & + \\
Motility & + & Arabinose & \\
Oxidase & + & Indole & + \\
Glucose APW & + & Voges Proskauer & + \\
Glucose O/F & & Gelatin hydrolysis & + \\
& Fermentativ & Catalase & + \\
Simmons citrate & + & Antibiotic sensitivity & \\
ONPG for â galactosidase & + & Ampicillin & Resistant \\
Arginine dihydrolase & + & Chloramphenicol & Sensitive \\
Lysine decarboxylase & + & & \\
\hline
\end{tabular}




\section{RAPD Profile}

The thermal cycle regime optimized for the PCR consisted of denaturation at $92^{\circ} \mathrm{C}$, primer annealing at $37^{\circ} \mathrm{C}$ and primer extension at $72^{\circ} \mathrm{C}$, and each step for duration of one minute. In our attempt to reduce the background banding, the annealing temperature was increased to $55^{\circ} \mathrm{C}$, and it gave clear reproducible bands. Amplification of the DNA from each of the 28 isolates with the five primers named earlier produced a total of 46 amplicons, which were consistent and appeared as distinct bands on agarose gel after electrophoresis. The RAPD fingerprints of the isolates generated by these random primers OPA-01 and OPA-10 are given in Fig. (1-2).

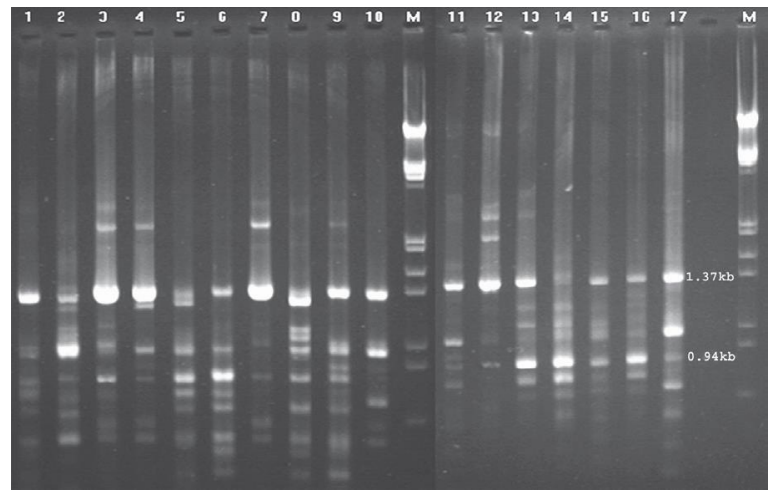

Figure1. RAPD pattern of A.hydrophila isolates generated by primer OPA-01. Lane 1-17: Ah1Ah17 isolates; M:Marker.

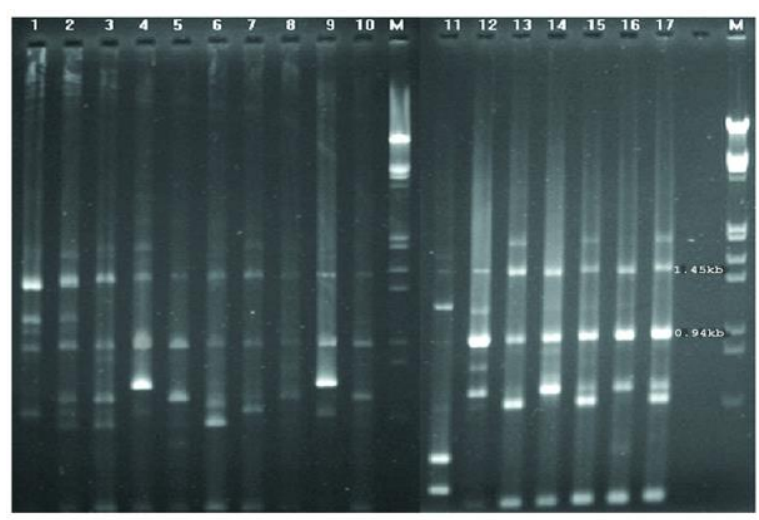

Figure 2. RAPD pattern of A.hydrophila isolates generated by primer OPA-10. Lane 1-17: Ah1Ah17 isolates; M: Marker.
The amplicons ranging from $2.5 \mathrm{~kb}$ on the higher side to approximately $0.5 \mathrm{~kb}$ on the lower side (as determined from the relative mobility of marker DNA $v i z ., \lambda$ DNA cut with HindIII /EcoR I) were only considered for the POPGENE analysis.

The OPA-01 produced 12 amplicons, which were scorable as distinct bands in the gel. Whereas two of the amplicons were produced by all the isolates, ten amplicons showed variation between isolates. The amplicons shared by all the isolates were 0.94 $\mathrm{kb}$ and $1.37 \mathrm{~kb}$ size. Seven amplicons were generated by OPA03 , which were within the range of $1.584 \mathrm{~kb}$ to $0.83 \mathrm{~kb}$. OPA-04 produced ten amplicons ranging in size from $2.5 \mathrm{~kb}$ to $0.55 \mathrm{~kb}$. OPA- 05 produced a total of six amplicons and OPA-10 produced 11 numbers of amplicons with size ranging from $1.9 \mathrm{~kb}$ to $0.5 \mathrm{~kb}$. With primer OPA-10, $0.94 \mathrm{~kb}$ and $1.45 \mathrm{~kb}$ amplicon was common to all the isolates. 
Polymorphism of the RAPD pattern was quite apparent among the different isolates. The RAPD fingerprint pattern was unique for each of the isolates. Comparison of the amplicons at each of the 46 loci indicated that all but four were polymorphic. The non-polymorphic loci were of primers OPA-01 and OPA-10. However, perusal of the banding pattern indicates that there were a number of fragments, which were homogenous among many of the isolates. The POPGENE analysis indicated that the overall polymorphism was $95.65 \%$. All the primers except OPA-01 and OPA-10 were highly discriminatory. The two monomorphic loci each of OPA-01 and OPA -10, with fixed allele viz., $1.37 \mathrm{~kb}, 0.94 \mathrm{~kb}$ and $1.45 \mathrm{~kb}, 0.94 \mathrm{~kb}$ respectively, are common to A. hydrophila. These fragments may be utilized for species-specific marker development, only if amplification of other aeromonads are also examined with these primers OPA-01 and OPA -10 .

\section{Similarity Index, Genetic Distance and Phylogenetic Relationships}

The average similarity index between Aeromonas hydrophila isolates was calculated as Nei's original measures of genetic identity and genetic distance, considering all the amplicons resulting from all the primers. The coefficient of genetic identities ranged from 0.413 to 0.848 , most of them were of high magnitude. Estimates of genetic distances were of lower magnitude. However, no correlation in genetic distance/similarity could be made between isolates from moribund fishes and those from brackishwater farms.

\section{Cellular Protein profile}

Soluble cellular proteins extracted from the isolates and resolved through SDSPAGE analysis are presented in Fig. 3.

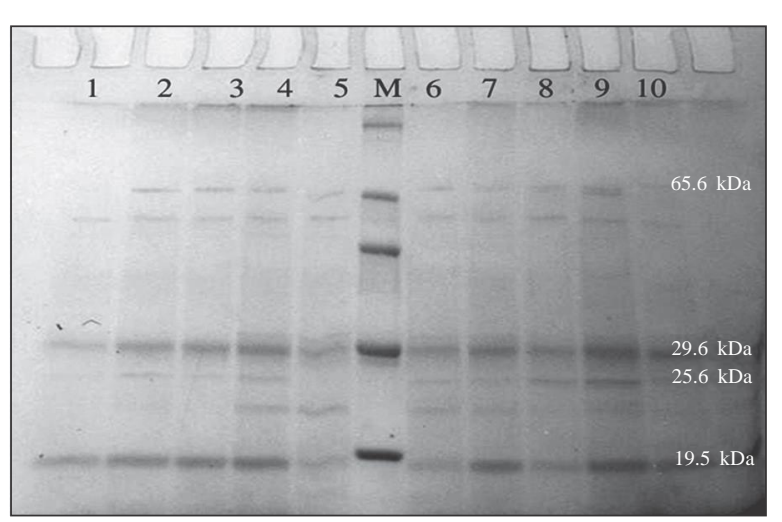

Figure 3.Cellular protein profile of A.hydrohila resolved through SDS PAGE. Lane 1-10:Ah1Ah10 isolates; M: Marker.
No significant polymorphism was evident through PAGE as all the isolates revealed more or less uniform profile. Four protein bands of molecular size viz., $19.5 \mathrm{kDa}$, $25.6 \mathrm{kDa}, 29 \mathrm{kDa}$ and $65.6 \mathrm{kDa}$ were shared by all the isolates in the study.

\section{Discussion}

Epidemiological tracking of A. hydrophila of aquaculture systems requires evaluation of genetic diversity and phylogenetic relationship among the isolates. 
Since the conventional methods are time consuming compared to the molecular tools, the potential of RAPD analysis and the cellular protein profile for characterization and evaluation of heterogeneity in A. hydrophila was assessed.

The study revealed that the RAPD profiles are highly discriminatory between all the isolates. RAPD has wide genomic coverage unlike amplification using specific primers and hence it has higher discrimination. RAPD techniques have many advantages over the conventional methods and other molecular techniques. It does not require any prior information on the sequence of the DNA being characterized. The RAPD technique requires the least quantity of DNA among the various techniques. Miyata et al. (1995) observed that the DNA required for RAPD is less than one hundredth of the amount required for other methods. We were able to generate reproducible RAPD profiles with as little as 20ng of DNA per PCR reaction in the study.

The DNA fingerprint pattern based on RAPD profiles revealed considerable amounts of polymorphism. Each isolate produced a unique pattern leading to absolute polymorphism. Comparison of individual amplicons revealed considerable variation between isolates by way of variations in size and number of amplified fragments. The polymorphism of the amplified fragments in this study was very high $(95.65 \%)$ with only four amplicons out of 46 being shared by all the isolates. Thus, the discriminating ability of the RAPD fingerprint observed in this study make it an ideal tool for evaluating population genetic diversity of the microbial populations within species. Molecular characterization of A.hydrophila strains from Japan by Miyata et al. (1995) also revealed considerable heterogeneity within the species. Results of this study corroborate the observation by other workers that motile aeromonads are genetically diverse (MacInnes and Trust, 1979) and antigenically very heterogenous (Mulla and Millership 1993). RAPD-PCR fingerprints have been used for typing and differentiation of bacteria and increasingly, for the study of genetic relationships between strains and species of microorganisms, plants and animals. The analysis of such fingerprints is based upon the assumption that co-migration of amplicons does not occur and that any given band contains a single amplicon. Co-migration of RAPD-PCR amplicons from A. hydrophila has been discussed earlier by Oakey et al. 1998. However, this was not observed in the present study.

This study points towards the presence of considerable genetic heterogeneity among the isolates even though they belong to the same species and are phenotypically homogenous as revealed by morphological and biochemical characterizations. This is quite possible. The morphological and biochemical characterization depend on the coding region of DNA, and any sequence changes in the regions are subjected to natural selection and culling. Very few of the variants, which have selective advantage, are only allowed to get established in the population and result in heterogeneity. Whereas, major portion of the DNA in the cell is the non-coding region that can accumulate genetic variation as 
they are not subjected to natural selection and therefore, accumulate variations, which can be detected by nucleic acid based techniques.

As expected in the light of the above statement cellular protein profile resolved through SDS- PAGE could not reveal intraspecies variation, as the profiles of all the isolates were more or less uniform. Hanninen et al. (1995) also reported a similar condition in A.salmonida from 28 Finnish strains with uniform SDS pattern among all the isolates studied, whereas the genetic differentiation could be generated with RAPD markers. Das et al.(2005) also has reported the use of SDS PAGE in Protein fingerprinting of A.hydrophila and they have revealed the genetic similarity between strains and reference strain (MTCC 646). They have observed unique clear and distinct bands in different local and reference strains of A.hydrophila, which they have suggested as suitable for molecular identification. These protein bands were of molecular weight 19.5, 23.5, 25.6, 32.4, 36.1, 41.2, 65.6,71.3, 72.9 and 86.2 $\mathrm{kDa}$. Among the common fragments determined in our study, bands of molecular size viz., $19.5 \mathrm{kDa}, 25.6 \mathrm{kDa}, 29$ $\mathrm{kDa}$ and $65.6 \mathrm{kDa}$ were shared by all the $A$. hydrophila isolates.

\section{Conclusion}

Search for species-specific amplicons that could be used as molecular markers of A. hydrophila pointed towards the amplicons generated by OPA-1 and OPA-10. However, the species specificity can be confirmed only by checking these primes with isolates of other aeromonads. The occurrence of large number of RAPD genotypes in the species indicating intraspecific genetic diversity which remain hidden with other methods of characterization especially, cellular protein profiling, reflect the potential and sensitivity of this approach for population genetic and systematic studies. Hadrys et al. (1992) has made a similar conclusion after carrying out RAPD studies in crabs. The results show that protein fingerprinting has the potential to differentiate Aeromonas species, but the low variation indicates that this technique is not efficient for the characterization of strains within a species. Conversely, RAPD fingerprinting allows the identification of strains but the high variability limits its potential as an aiding method for species identification.

\section{Acknowledgement}

The authors thank Dr. Mohan Joseph Modayil, Director CMFRI, Cochin, for providing necessary facilities and Dr. R. Paulraj, Principal Scientist, for encouragement. The author acknowledges CIFE/ICAR for the financial assistance received during the tenure of this work.

\section{References}

Austin, B. and D. Austin. 1993. Bacterial Fish Pathogens: Disease in farmed and wild fish (Ed. Laird, M.) Ellis 
Chester, F.D.1901. A manual of determinative Bacteriology. The Macmillan Co., New York, pp. 1-401.

Covadonga R.A., Maria Jesus Pujalte, Esperanza Garay and Rosa Aznar. 1998. Genetic relatedness among Environmental, Clinical and Diseased-Eel Vibrio vulnificus Isolates from Different Geographic regions by Ribotyping and Randomly Amplified Polymorphic DNA PCR. Applied and Environmental Microbiology 64(9): 3403-3410.

Das,B.K.,Surya Kanta Samal,Biswa Ranjan Samantaray and Prem Kumar Meher, 2005. Protein fingerprinting profiles in different strains of Aeromonas hydrophila isolates from diseased freshwater fish. World Journal of Microbiology and Biotechnology 21:587-591.

Hadrys, H., M. Balick, and B. Schierwater. 1992. Applications of random amplified polymorphic DNA (RAPD) in molecular ecology. Molecular Ecology 1(1): 55-63.

Hanninen,M.L., J.Ridell and V.Hirvela-Koski. 1995.Phenotypic and molecular characteristics of Aeromonas salmonicida sub sp. salmonicida isolated in Southern and Northern Finland. Journal of Applied Bacteriology 79:12-21.

Inglis, V., R.J. Roberts, and N.R. Bromage. 1993. Bacterial diseases of fish. Blackwell Scientific Publications Oxford.

Laemmeli, U.K.1970. Cleavage of structural protein during the assembling of the head of bacteriophage. Nature 227: $680-685$.

Lawrence, L.M., J. Harvey and A. Gilmour. 1993. Development of a Random Amplification of Polymorhic DNA Typing Method for Listeria monocytogenes. Applied and Environmental Microbiology 59(9): 3117-3119.

MacInnes, J.I., T.J. Trust and J.H. Crosa, 1979. Deoxyribonucleic acid relationships among members of the genus Aeromonas. Canadian Journal of Microbiology 25 (9): 579-586.

Mc Lean R.G., S.Rubaica, CAB Hughes, S.M.Engstrom and R.C.Johnson. 1993. Isolation and characterization of Borrelia burgdorferi from the blood of a bird. Journal of Clinical Microbiology 31 (8): 2038-2043.

Miyata, M., T. Aoki, V. Inglis, T.Yoshida and M. Endo, 1995. RAPD analysis of Aeromonas salmonicida and Aeromonas hydrophila. Journal of Applied Bacteriology 79(2): 181-185.

Mulla, R. and S. Millership, 1993. Typing of Aeromonas spp. by numerical analysis of immunoblotted SDS-PAGE gels. Journal of Medical Microbiology 39:325-333

Murray, M.G. and W.F. Thompson. 1980. Isolation of Genomic DNA from Bacteria. Nucleic Acids Research 8 : 4321-4325.

Oakey HJ, Gibson LF, George A.M. 1998. Co-migration of RAPD-PCR amplicons from Aeromonas hydrophila FEMS Microbiology Letters (1) 164(1): 35-8.

Olafse, J.A., H.V. Mikkelsen, H.M. Giaver, and G.H. Hansen. 1993. Indigenous bacteria in haemolymph and tissues of marine bivalves at low temperatures. Applied and Environmental Microbiology 59: 1848-1854.

O'hlei, Gilles Olivier and Richard Powell. 2000. Genetic diversity of the fish pathogen Aeromonas salmonicida demonstrated by Random Amplified Polymorphic DNA and Pulse Field Gel Electrophoresis analysis. Diseases of Aquatic Organisms 39(2): 109-119.

Pattanayak, D., K. Swarup, P.Chakrabarti, Ananda Kumar and Prakash S Naik. 2001. Characterization of genetic diversity of some serovars of Bacillus thuringiensis by RAPD. Indian Journal of Experimental Biology 39(9): 897-901.

Stanier, R.Y. 1943. A note on the taxonomy of Proteus hydrophilus. Journal of Bacteriology 46(2): 213-214.

Yeh, C. Francis, R.C. Yang, Boyle, B.J. Timothy, Z-H Ye , Mao and X. Judy. 1997. POPGENE, the userfriendly shareware for population genetic analysis. Molecular Biology and Biotechnology Centre, University of Alberta, Canada. 